\title{
Esterilização cirúrgica feminina no Brasil, 2000 a 2006: aderência à lei de planejamento familiar e demanda frustrada*
}

\author{
André Junqueira Caetano*
}

\begin{abstract}
A Lei n. 9.263, de 1996, findou uma omissão histórica do Estado brasileiro no âmbito do planejamento familiar, além de legislar a provisão de esterilização cirúrgica no sistema público de saúde. Já as portarias do Ministério da Saúde n. 144, de 1997, e n. 48, de 1999, contêm critérios potencialmente restritivos à obtenção da laqueadura tubária e à sua obtenção nos termos regulatórios. Se a não aderência à regulamentação relaciona-se ao período de aconselhamento de 60 dias e à proibição da laqueadura até 0 42ํ dia após o parto, parte das recusas dos profissionais envolvidos na provisão da laqueadura é consequência das percepções e posturas destes sobre critérios tais como idade e número de filhos e sobre as eventuais implicações da esterilização para a requisitante. As recusas explícitas ou implícitas nesta filtragem resultam em uma demanda frustrada. Esta lógica aplica-se ao nível municipal da gestão da saúde, refletindo-se na inexistência de serviços credenciados na maioria dos municípios brasileiros com capacidade hospitalar para oferecer o procedimento. Empregando os dados da PNDS 2006 e as Autorizações de Internação Hospitalar, este artigo analisa, primeiramente, a aderência à regulamentação das laqueaduras tubárias realizadas no SUS no período 2000-2006 e a dimensão da rede de municípios com serviços credenciados em 2006 e 2013. A demanda frustrada é estudada a partir das informações da PNDS 2006 sobre as tentativas malogradas devido à recusa do serviço procurado, à não obtenção sem especificação do motivo e à não concordância do cônjuge.
\end{abstract}

Palavras-chave: Saúde reprodutiva. Lei de planejamento familiar. Contracepção. Laqueadura tubária. Demanda frustrada. Brasil.

\footnotetext{
* O presente trabalho foi realizado com apoio do Conselho Nacional de Desenvolvimento Científico e Tecnológico - CNPq Brasil. 0 autor agradece aos pareceristas pelas pertinentes e valiosas considerações.

${ }^{* \star}$ Pontifícia Universidade Católica de Minas Gerais - PUC Minas, Belo Horizonte-MG, Brasil (acaetano@pucminas.br).
} 


\section{Introdução}

Os anos 1980 e o primeiro quinquênio da década de 1990 foram marcados pela disseminação da laqueadura tubária como o principal método contraceptivo no Brasil. Já o decênio entre as Pesquisas Nacionais de Demografia e Saúde da Criança e da Mulher (PNDS) de 1996 e 2006 foi caracterizado pela diminuição da proporção de mulheres de 15 a 49 anos em união laqueadas, passando, nesse período, de 40,1\% para 29,1\% (CAETANO, 2010), no contexto da vigência da Lei n. 9.263, referente ao planejamento familiar, promulgada em 1996 (BRASIL, 1996) e sancionada em 1997.

Estudos realizados nos anos que se seguiram à regulamentação da lei do planejamento familiar indicam que esta, de forma não antecipada, engendrou obstáculos ao acesso à laqueadura tubária no âmbito do Sistema Único de Saúde (SUS). Tais obstáculos estariam relacionados com a adoção, por parte dos serviços e médicos, de critérios de idade e número de filhos mais restritivos do que os presentes na portaria regulatória, necessidade de obter a anuência por escrito do cônjuge, demora entre a solicitação e a realização do procedimento, proibição da laqueadura no parto e pós-parto, além de uma cobertura territorial limitada de serviços médicos do SUS credenciados para ofertar a esterilização cirúrgica feminina.

À luz desses estudos, revisados na seção a seguir, este artigo aborda três questões sobre a prática da laqueadura tubária no Brasil,no período que se estende de 2000 a 2006. A primeira diz respeito à participação de hospitais do SUS ou vinculados ao sistema público, em comparação com serviços privados, na oferta de esterilização cirúrgica feminina e ao grau de aderência às regulações da Lei n. 9.263 quanto às laqueaduras tubárias realizadas no SUS. A segunda refere-se à potencial limitação territorial da rede de municípios com hospital com capacidade para realizar a esterilização cirúrgica feminina e, ao mesmo tempo, habilitado para provê-la. Por fim, a terceira está relacionada com a constituição de uma demanda frustrada por laqueadura tubária.

Para responder à primeira questão, dimensionou-se, inicialmente, a oferta de esterilização cirúrgica feminina em hospitais do SUS ou afiliados a ele, entre 2000 e 2006, por meio das Autorizações de Internação Hospitalar $(\mathrm{AlH})^{1}$ processadas e pagas, segundo o município de internação. Uma vez dimensionada, esta oferta foi contraposta ao total - estimado a partir dos dados da PNDS 2006 - de mulheres entre 15 e 49 anos de idade alguma vez unidas esterilizadas cirurgicamente em serviços do SUS, cujos procedimentos são compatíveis com a legislação no que se refere à relação com o parto e ao período mínimo de aconselhamento.

Utilizando-se as AlH de laqueadura tubária processadas e pagas, segundo o município de internação, como proxy da existência de serviço credenciado para prover a esterilização cirúrgica feminina em determinado município, é possível identificar e comparar o número de municípios, por região, com hospitais do SUS, ou afiliados ao sistema público, relativamente ao número de municípios com hospitais em que foram processadas e pagas AlH obstétricas,

\footnotetext{
${ }_{1}^{1}$ A AlH é o registro administrativo do Sistema de Informação Hospitalar do SUS para acompanhamento e pagamento de internações e procedimentos cirúrgicos. Suas características e especificidades são apresentadas na segunda seção deste artigo.
} 
excetuados os partos normais, e de clínica cirúrgica, isto é, com capacidade hospitalar potencial para a realização do procedimento. Este exercício foi feito para 2006 e, como contraponto mais recente, também para 2013. É importante esclarecer que não se trata de análise espacial stricto sensu, mas sim para estabelecer a proporção de municípios com serviço médico credenciado de acordo com as regulamentações da Lei n. 9.263 em relação aos potencialmente aptos a oferecer o procedimento nos dois anos em questão. Ressalvese que a ausência de registro de AlH de laqueadura tubária em um dado município em determinado ano não significa, necessariamente, que ali não havia serviço credenciado.

Por fim, e como potencial consequência dos obstáculos derivados das regulamentações da Lei n. 9.263, este estudo identifica e dimensiona a demanda frustrada por esterilização cirúrgica feminina no país, utilizando as informações da PNDS 2006 sobre mulheres que tentaram obter o procedimento e não conseguiram. Estima-se a prevalência do uso dos métodos contraceptivos na hipótese de que as mulheres unidas de 15 a 49 anos, que tentaram fazer a esterilização e o serviço procurado negou, que tentaram e não conseguiram sem especificação da razão e as que os cônjuges não concordaram, foram bem-sucedidas em seu intento. Além de permitir a estimação desta distribuição hipotética do uso de métodos contraceptivos entre mulheres unidas de 15 a 49 anos, tais informações são importantes para ampliar o conhecimento sobre as características das mulheres e sobre os fatores associados ao insucesso da implantação de uma decisão reprodutiva, embora esta análise não seja objeto deste artigo.

A Lei n. 9.263 e as portarias que a regulamentam tratam da esterilização cirúrgica tanto feminina (laqueadura tubária) quanto masculina (vasectomia). Enquanto a prevalência de esterilização cirúrgica entre mulheres unidas de 15 a 49 anos de idade decresceu entre 1996 e 2006, a participação da vasectomia como método contraceptivo teve um aumento importante (PERPÉTUO; WONG, 2009). Ademais, esterilização cirúrgica não implica, necessariamente, a não utilização de preservativo masculino ou feminino. Fato é que a evolução da prática da vasectomia no âmbito do SUS merece uma análise específica. Porém, em face dos objetivos deste artigo, é necessário frisar que a esterilização cirúrgica feminina por laqueadura tubária realizada no SUS é o objeto e foco exclusivo do presente estudo. Além disso, diante da natureza dos dados utilizados, a análise empreendida refere-se ao universo de procedimentos realizados no período 2000-2006, não tratando, por conseguinte, de diferenciais regionais, sociodemográficos ou socioeconômicos no acesso à laqueadura tubária.

Na seção que se segue, a literatura pertinente é revisada de forma a contextualizar e fundamentar as três questões analisadas neste artigo. O dimensionamento da oferta de laqueaduras tubárias no âmbito do SUS, no período 2000-2006, e a comparação com as informações captadas pela PNDS 2006 são tratados na segunda seção. Posteriormente, comparam-se, por região, os municípios com AlH de laqueadura processada e paga em 2006 e 2013 em relação ao número de municípios com capacidade hospitalar potencial para a realização do procedimento. Para fins de uma contextualização mais atual, o número de laqueaduras realizadas no SUS no período 2007-2013 é apresentado e discutido ao fim 
desta seção. A estimação da demanda frustrada por laqueadura tubária, a partir dos dados da PNDS 2006, é o conteúdo da última seção. Este artigo se encerra com as considerações gerais sobre os achados, à luz da literatura pesquisada.

\section{Revisão da literatura}

A contracepção moderna foi o principal determinante próximo da queda da fecundidade no Brasil, a partir da década de 1960 (MARTINE, 1996), e a demanda crescente por regulação da fecundidade foi suprida principalmente pelo aumento da utilização da laqueadura tubária, a partir de 1980, especialmente nas áreas mais pobres e nos estratos de baixa renda (PERPÉTUO; WAJNMAN, 1998). Em 1986, 28,2\% das mulheres de 15 a 44 anos unidas eram esterilizadas cirurgicamente, proporção que passou para 40,1\%, em 1996, entre mulheres de 15 a 49 anos unidas (PERPÉTUO; WONG, 2009). Houve, portanto, um aumento substancial, entre 1986 e 1996, de mulheres em idade reprodutiva, em união, esterilizadas.

O aumento da prática de esterilização cirúrgica feminina nos anos 1980 intensificou a preocupação de gestores da saúde, movimentos sociais, pesquisadores e autoridades públicas com eventuais ações controlistas no Brasil (GELEDÉS, 1991; PERNAMBUCO, 1992; BERQUÓ, 1993). Suspeitava-se que clínicas de planejamento familiar financiadas por instituições internacionais estavam oferecendo laqueaduras gratuitas ou a preços módicos por indicação médica ou social. Em 1992, o Congresso Nacional instalou Comissão Parlamentar de Inquérito (CPI) para investigar o fenômeno da esterilização cirúrgica feminina em massa no Brasil (BRASIL, 1993). A comissão estabeleceu nove itens nos quais focalizou a investigação, entre os quais sobressaíam motivações racistas, participação de interesses internacionais e a oferta de métodos contraceptivos reversíveis para a população de baixa renda.

No relatório final, publicado em 1993, a CPI concluiu que a real disponibilidade de métodos contraceptivos para a população de baixa renda estava longe de ser efetivo e serviços de planejamento familiar inexistiam ou eram inacessíveis para a maior parte da população (BRASIL, 1993). De fato, quase dez anos antes, Barroso (1984) já advertia que determinantes específicos, tais como a estrutura do atendimento hospitalar e a ausência de políticas públicas que fizessem face à crescente demanda por contracepção moderna, levavam as mulheres a elegerem a laqueadura tubária como método de preferência.

Seja como for, neste período a laqueadura tubária não era reembolsável pelo sistema público de saúde (BERQUÓ, 1995). Para cobrir os custos e acobertar a intervenção cirúrgica nos hospitais do sistema público de saúde ou afiliados a ele, passou-se a acoplá-la a uma cesariana ou registrar a realização de outro procedimento pago pelo SUS (MERRICK; BERQUÓ, 1983; CAETANO; POTTER, 2004). A combinação dessas características - pagamento ou favor e acoplamento à cesariana ou de intervalo - variava regionalmente conforme o nível de renda e o peso do setor privado na assistência médica. No Nordeste, a proporção de laqueaduras de intervalo obtidas gratuitamente como favor político teve um peso muito maior do que na Região Sudeste (CAETANO; POTTER, 2004). 
A partir das análises da PNDS de 1996, as perspectivas que enfatizavam determinantes específicos deram lugar a abordagens mais complexas, nas quais se interligavam as deficiências do sistema de saúde, o comportamento dos médicos e profissionais de saúde, a posição recalcitrante por parte dos parceiros e maridos em relação à contracepção, desinformação sobre o próprio corpo e sobre a atuação dos métodos contraceptivos, falta de acesso ao leque de métodos reversiveis e pobreza (BERQUÓ, 1995; DINIZ et al., 1998). Permeando todos esses aspectos estava o reconhecimento de que havia uma grande demanda e escassas alternativas contraceptivas. Foi esse conjunto de elementos e acontecimentos que propiciou a aprovação, em 1996, da Lei n. 9.263, conhecida como lei do planejamento familiar.

Em 20 de agosto de 1997, o então presidente Fernando Henrique Cardoso promulgou a Lei n. 9.263, aprovada em 12 de janeiro de 1996, tornando a vasectomia e a laqueadura tubária procedimentos hospitalares ofertados gratuitamente no Sistema Único de Saúde (SUS), desde que cumpridos os requisitos determinados. De acordo com a Portaria n. 144, da Secretaria de Assistência a Saúde, Ministério da Saúde, de 20 de novembro de 1997, que regula a Lei n. 9.263, para ter direito ao procedimento de esterilização cirúrgica em um serviço público, é necessário ter capacidade civil plena e no mínimo 25 anos de idade ou dois ou mais filhos vivos (BRASIL, 1997). ${ }^{2}$ Em ambas as situações, a demandante deve apresentar a anuência do parceiro com a respectiva assinatura. Foi estabelecido, ainda, um período de embargo à laqueadura tubária de 42 dias após o parto, para coibir a realização de partos cesáreos desnecessários. Somente são autorizadas laqueaduras pós-parto em casos de indicação médica, aborto e cesarianas sucessivas (BRASIL, 1999b).

Além disso, todo indivíduo que requeira a esterilização cirúrgica deve passar por um período de aconselhamento de 60 dias, durante o qual deverá ser informado sobre o procedimento e suas implicações, bem como sobre os métodos reversíveis. O serviço deve ser capaz de prover tais métodos. À autoridade estadual ou municipal com gestão plena do sistema de saúde cabem a aprovação e o credenciamento do serviço (BRASIL, 1999b; LUIZ; CITELI, 2000). Apenas os serviços do SUS devidamente certificados podem receber reembolso para os procedimentos hospitalares de laqueadura tubária e vasectomia.

A realização de laqueaduras tubárias no SUS seguindo as determinações da Lei n. 9.263 teve início efetivo em 1998, com 293 AlH registradas no Sistema de Informações Hospitalares (SIH/SUS). A partir de então, uma série de pesquisas e estudos foi realizada com o objetivo de investigar e avaliar o acesso à esterilização cirúrgica feminina, com ênfase no papel dos médicos, na perspectiva de gestores e na avaliação de usuários do sistema público de saúde que requereram a laqueadura tubária ou a vasectomia.

\footnotetext{
${ }^{2}$ o Código Civil Brasileiro de 1916 vigeu até 2002 e o Código Civil Brasileiro de 2002, vigente a partir de 2003, modificou as condições que definem o cessamento da minoridade e capacidade civil relativa e plena. A relação entre capacidade civil plena e idade, presente nos Códigos Civis Brasileiros, é discutida na última seção deste artigo.
} 
Pesquisa pioneira foi levada a cabo em 1999, para avaliar os efeitos da Lei n. 9.263 na Região Metropolitana de São Paulo (LUIZ; CITELI, 2000). Entre julho e dezembro daquele ano, foram entrevistados os responsáveis por 23 serviços de saúde que ofereciam laqueadura tubária e vasectomia. A principal conclusão do estudo foi que a lei não havia acarretado mudanças significativas na prática de esterilização cirúrgica feminina. Segundo os entrevistados, a demanda por laqueadura tubária havia crescido após a aprovação da lei e a provisão dessa demanda competia com a necessidade devido a condições médicas da paciente. Segundo as autoras, os entrevistados reportaram que os serviços não tinham capacidade para suprir a demanda total, o que se intensificou com a proibição da laqueadura pós-parto em fevereiro de 1999 (BRASIL, 1999a). Além disso, o estudo sugere que os médicos eram pouco aderentes à legislação, utilizando critérios próprios, definidos caso a caso.

Berquó e Cavenaghi (2003) analisaram a implementação da nova legislação de planejamento familiar, especialmente da esterilização cirúrgica voluntária, com o objetivo de verificar se os direitos reprodutivos de mulheres e homens estavam sendo atendidos. As autoras realizaram pesquisa longitudinal com uma amostra de 159 requerentes em Palmas, Recife, Belo Horizonte, São Paulo, Curitiba e Cuiabá. Do lado da oferta, foram entrevistados profissionais e gestores de saúde. Após seis meses de acompanhamento, 25,8\% das mulheres e $31 \%$ dos homens haviam obtido o procedimento. Pouco mais da metade das mulheres e dois quartos dos homens que não obtiveram a cirurgia mencionaram a burocracia e o desrespeito à lei por parte dos serviços e dos médicos como razões para o insucesso. Segundo as autoras, os resultados indicavam que a prática usual da esterilização cirúrgica pouco havia mudado após as portarias que regulam a Lei n. 9.263.

Em estudo realizado por Vieira e Souza (2009), verificou-se que parte dos solicitantes da esterilização cirúrgica pelo SUS em Ribeirão Preto não obtinha o procedimento. O insucesso, segundo os autores, poderia ser devido à desistência ou ao adiamento em decorrência do aconselhamento, ou em razão de obstáculos originados no sistema de saúde. Vieira e Ford (2004) analisaram essas hipóteses entrevistando, em 2004, 230 indivíduos que demandaram e não obtiveram cirurgia de esterilização no período de 1999 a 2004, comparando-os com 297 indivíduos que a obtiveram. Entre os que não conseguiram a cirurgia, 10\% ainda tinham expectativa de obtê-la. Dos 207 restantes, 71\% decidiram adiar e 29\% encontraram obstáculos. Segundo os autores, o longo período de aconselhamento - em média oito meses entre os que obtiveram a cirurgia - era a razão mais provável para 45\% desses indivíduos, os quais alegaram falta de tempo, problemas burocráticos, ter procurado outro serviço e estar aguardando ser chamado.

Potter et al. (2003) realizaram pesquisa longitudinal nas Regiões Metropolitanas de Porto Alegre, Belo Horizonte e Natal e no município de São Paulo. Foram entrevistadas 1.612 mulheres grávidas com idades entre 18 e 40 anos. A amostra foi estratificada segundo a natureza do serviço, se público ou privado, na proporção de dois para um. As entrevistas foram realizadas no momento do recrutamento, um mês antes da data marcada para o parto e um mês depois deste. Mulheres que informaram, em uma das duas primeiras entrevistas, que 
não queriam mais filhos foram indagadas sobre como preveniriam futuras gravidezes. Aquelas que relataram querer a esterilização foram inquiridas se planejavam obtê-la imediatamente após o parto ou mais tarde. Na fase após o parto, foi encontrada uma proporção substancial de mulheres que desejavam a esterilização pós-parto. As pacientes de hospitais públicos apresentaram uma chance significativamente menor de esterilização se comparadas às pacientes de hospitais privados. Os autores argumentam que a Lei n. 9.263 não deve ter reduzido as desigualdades de acesso à laqueadura tubária e, de forma não antecipada, incentivava a realização de cesarianas desnecessárias.

Com base em pesquisa realizada nos municípios da Região Metropolitana de Campinas, Carvalho et al. (2007) compararam homens e mulheres que foram esterilizados cirurgicamente antes e depois da regulamentação da Lei n. 9.263. Segundo os autores, os resultados, apesar de não conclusivos, indicam que as mudanças esperadas a partir da vigência da legislação não ocorreram de acordo com as expectativas, em especial no que se refere à redução de laqueaduras tubárias acopladas a cesarianas e realizadas no pós-parto imediato. Eles também identificaram dificuldades importantes para o atendimento da demanda da esterilização cirúrgica, principalmente no nível de atenção primária. Tais dificuldades estariam relacionais à "falta de infraestrutura e problemas no encaminhamento aos serviços de referência”, o que tende a gerar um aumento no tempo de espera tanto para a laqueadura tubária quanto para a vasectomia (CARVALHO et al., 2007, p. 2914). Deve-se considerar, a este respeito, que o tempo de espera pelo procedimento associa-se positivamente à chance de desistência da solicitante no decorrer do processo.

Também na Região Metropolitana de Campinas, Osis et al. (2009) realizaram estudo qualitativo com profissionais médicos e gestores municipais de serviços de saúde envolvidos com a provisão de esterilização cirúrgica em quatro municípios. Entre as percepções dos entrevistados, os autores ressaltam as críticas aos critérios legais relativos à idade e ao número de filhos. De acordo com os autores, "a tendência dos profissionais entrevistados foi considerar que [esses critérios] contribuem para o arrependimento pós-esterilização, pois permitem que as cirurgias sejam realizadas em pessoas bem jovens e com poucos filhos", o que seria indicativo de uma postura resistente a tais critérios por parte desses profissionais (OSIS et al., 2009, p. 632).

Segundo Carvalho et al. (2007, p. 2915), em face de poucas análises sobre outras regiões, pode-se considerar a Região Metropolitana de Campinas um parâmetro para o restante do país, pois esta é uma das regiões que "apresentam os melhores indicadores de atenção à saúde”. De fato, é factível supor que os problemas identificados na Região Metropolitana de Campinas sejam mais exacerbados em outras áreas do país.

Para estes problemas existirem, é necessário que exista serviço de planejamento familiar no âmbito do SUS nos termos da legislação, como é o caso da Região Metropolitana de Campinas. Entretanto, a falta de estímulos para implantação, no nível municipal, de serviços de planejamento familiar no âmbito do SUS tende a restringir o acesso à esterilização cirúrgica feminina territorialmente. De acordo com Amorim et al. (2008, p. 111), apesar de ter ocorrido 
aumento importante no número de hospitais credenciados para realização de laqueadura tubária desde a regulamentação da Lei n. 9.263, passando de 135 hospitais em outubro de 1999 para 1.395 em janeiro 2007, "os serviços continuaram mais concentrados nos maiores centros urbanos". Deve-se levar em conta que o aumento do número de hospitais credenciados não está diretamente relacionado à ampliação do número de municípios com hospital credenciado. Sobre este ponto, é importante ter em mente que o foco deste artigo compreende os municípios.

Em síntese, as regulamentações da lei do planejamento familiar tornaram obrigatória a apresentação do consentimento do cônjuge, estabeleceram um período mínimo de espera de 60 dias e proibiram a laqueadura tubária no parto e pós-parto. Do lado da oferta, para o credenciamento do serviço médico-hospitalar, deve ser organizado um programa de informação e aconselhamento e os métodos reversíveis devem ser disponibilizados. De acordo com os estudos examinados, esses requisitos tendem a constituir-se como obstáculos à obtenção da laqueadura tubária no SUS por eventual oposição do parceiro, por desistência durante o período de espera, por dificuldade em iniciar o processo mais de um mês e meio após o nascimento da criança, por discordância do profissional com os critérios da lei e pela falta de serviço credenciado. Esses fatores são determinantes para que a prática da laqueadura tubária observada no período posterior à Lei n. 9.263 não tenha se alterado significativamente e, portanto, para a constituição de um descompasso, no SUS, entre demanda e oferta dentro dos critérios da lei.

\section{Laqueaduras tubárias no período 2000-2006: comparação entre Autorizações de Internação Hospitalar e PNDS 2006}

A fim de proceder à comparação entre as AlH de laqueadura tubária processadas e pagas, segundo o município de internação, e as frequências estimadas de esterilização cirúrgica feminina a partir dos dados da PNDS 2006 para o período 2000-2006, são necessários esclarecimentos conceituais e metodológicos concernentes à definição do período de análise, ao registro administrativo e à expansão de estimativas amostrais para o total da população de interesse.

Com relação ao período de análise, não foram incluídos os anos de 1998 e 1999 para evitar a sobreposição normativa, uma vez que a Portaria n. 48, do Ministério da Saúde, que veda a laqueadura tubária até 42ํ dia após o parto, foi emitida em 11 de fevereiro de 1999 (BRASIL, 1999b). Portanto, a restrição da análise ao período 2000-2006 visa considerar apenas as esterilizações tubárias realizadas em hospital público ou particular afiliado ao SUS que não poderiam ter sido feitas no parto ou no período de 42 dias após o parto.

A Autorização de Internação Hospitalar (AIH) é o registro administrativo referente a tratamentos e procedimentos clínicos e cirúrgicos e constitui o pilar do Sistema de Informações Hospitalares (SIH). Para solicitar a AlH, o profissional que realiza o atendimento necessita providenciar o Laudo para Solicitação de AlH contendo informações sobre o paciente, exames, resultados de exames, diagnóstico e justificava para internação (BRASIL, 2012). Gerada a 
AlH, o paciente pode ser internado. O número de identificação da AlH do paciente é exclusivo para a mesma internação (SANTOS, 2009). Ao final do tratamento, registra-se, no hospital, com base nas regras presentes na Tabela Nacional de Procedimentos SUS, o atendimento prestado. A tabela de procedimentos estabelece, também, os valores para o pagamento de diárias, medicamentos, exames, serviços hospitalares e serviços médicos (BRASIL, 2012).

Entre as informações de identificação da AlH, são registrados o município de internação e o de residência do paciente. 0 ano e o mês de processamento informam o período de referência da AlH, o qual coincide com o mês de ocorrência da alta, óbito ou transferência. ${ }^{3}$ Desse modo, as AlH aqui analisadas são aquelas denominadas Laqueadura Tubária e Parto Cesáreo com Laqueadura Tubária ${ }^{4}$ processadas e pagas, segundo o município de internação, nos anos de referência do período 2000-2006 e em 2013.

Para dimensionar a proporção de laqueaduras tubárias registradas como AlH processadas e pagas, foram utilizados os dados da PNDS 2006 para as mulheres alguma vez unidas laqueadas entre 2000 e 2006, aplicando-se os respectivos fatores de expansão. Os percentuais e as frequências expandidas baseiam-se em um número relativamente pequeno de casos, o que implica maior imprecisão da estimativa, isto é, maior dispersão em torno do valor esperado. Tendo em vista que a amostra da PNDS 2006 é probabilística aleatória com desenho amostral complexo, é necessário não somente usar o fator de ponderação apropriado, mas também incorporar o desenho amostral na estimação das medidas de interesse. ${ }^{5}$ Ao se considerar o desenho amostral, é possível obter medidas de dispersão que informam a variabilidade dessas medidas.

Para incorporar o desenho amostral nas estimações, utilizou-se, em todas as tabulações com dados da PNDS 2006, a informação para conglomerado e estrato. Para as estimativas em que frequências expandidas foram utilizadas na comparação com os registros administrativos de $\mathrm{AlH}$, informam-se o intervalo de confiança de 95\% e o coeficiente de variação. 0 coeficiente de variação é dado pela divisão do erro padrão da medida amostral pelo seu valor, constituindo-se, portanto, em um indicador relativo de dispersão (BUSSAB; MORETTIN, 2010). O erro padrão, de outra forma, é uma medida absoluta de dispersão. A inclusão do intervalo de confiança e do coeficiente de variação justifica-se porque a variabilidade informada pelo erro padrão pode ser de pequena magnitude e a variabilidade relativa ser mais ampla. Além disso, por ser uma medida relativa, o coeficiente de variação permite a comparação entre as medidas obtidas (BUSSAB; MORETTIN, 2010). A informação conjunta dessas duas estatísticas de dispersão permite uma avaliação mais acurada das limitações e do risco ao se utilizar a frequência amostral expandida.

\footnotetext{
${ }^{3}$ Informações de Saúde (TABNET), Notas Técnicas. Disponível em 〈http://tabnet.datasus.gov.br/cgi/sih〉. Acesso em: 11 out. 2014.

${ }^{4}$ Até 2007 , a AlH de parto cesáreo com laqueadura tubária era denominada cesariana com laqueadura tubária em paciente com cesarianas sucessivas. A Portaria n. 2.848, de 6 de novembro de 2007, unificou os códigos e alterou denominações e especificações dos procedimentos ambulatoriais e hospitalares do SUS (BRASIL, 2007). Esta é a denominação utilizada neste artigo.

${ }^{5}$ Pesquisa Nacional de Demografia e Saúde da Criança e da Mulher - PNDS 2006: Aspectos metodológicos. Disponível em 〈http://bvsms.saude.gov.br/bvs/pnds/banco_dados.php〉. Acesso em: 10 abr. 2010.
} 
Aplicando-se o fator de expansão referente à mulher disponibilizado no banco de dados da PNDS 2006, obtêm-se 3.371.523 mulheres de 15 a 49 anos alguma vez unidas que foram cirurgicamente esterilizadas no Brasil, entre 2000 e 2006 (Tabela 1). Desse total, 66,2\% obtiveram o procedimento em um serviço do SUS, das quais 5,2\% pagaram pelo procedimento. Este resultado indica que os serviços do SUS foram a fonte de obtenção do procedimento para dois terços das laqueadas no período analisado. A preponderância do sistema público de saúde como a maior fonte de obtenção da laqueadura tubária, em 1996, também é observada a partir dos dados da PNDS 1996 (CAETANO, 2010).

TABELA 1

Distribuição das mulheres de 15 a 49 anos alguma vez unidas esterilizadas cirurgicamente, por condição de pagamento do procedimento, segundo natureza do hospital

Brasil - 2000-2006

\begin{tabular}{|c|c|c|c|c|c|}
\hline \multirow{2}{*}{ Natureza do hospital } & \multicolumn{3}{|c|}{ Pagou pela esterilização (\%) } & \multirow{2}{*}{$\begin{array}{c}\text { Total } \\
\text { (\%) }\end{array}$} & \multirow{2}{*}{$\begin{array}{c}\text { Frequência expandida } \\
\text { (ponderação normalizada } \\
\text { para o total da amostra) } \\
\text { (n. abs.) }\end{array}$} \\
\hline & Sim & Não & $\begin{array}{c}\text { Sem } \\
\text { resposta }\end{array}$ & & \\
\hline $\begin{array}{l}\text { Serviço público } \\
\text { Intervalo de confiança 95\% } \\
\text { Coeficiente de variação }\end{array}$ & $\begin{array}{r}5,2 \\
2,9-7,6 \\
10,7\end{array}$ & $\begin{array}{r}60,9 \\
55,6-66,1 \\
2,9\end{array}$ & $\begin{array}{r}0,1 \\
0,0-0,2 \\
49,6\end{array}$ & 66,2 & $2.248 .024(669)$ \\
\hline $\begin{array}{l}\text { Serviço privado } \\
\text { Intervalo de confiança 95\% } \\
\text { Coeficiente de variação }\end{array}$ & $\begin{array}{r}29,4 \\
24,7-34,0 \\
4,1\end{array}$ & $\begin{array}{r}4,5 \\
2,4-6,6 \\
9,2\end{array}$ & $\begin{array}{r}0,0 \\
- \\
-\end{array}$ & 33,8 & 1.150 .119 (342) \\
\hline Total & 34,6 & 65,3 & 0,1 & 100,0 & 3.398 .143 (1.011) \\
\hline
\end{tabular}

Fonte: Microdados da Pesquisa Nacional de Demografia e Saúde da Criança e da Mulher, PNDS 2006. Nota: $O$ total é obtido pela soma das células da distribuição conjunta entre natureza e pagamento.

É necessário examinar em que medida as laqueaduras tubárias do período foram oferecidas de acordo com os critérios estabelecidos na letra da lei. A Tabela 2 apresenta a proporção de laqueaduras realizadas no SUS, sem pagamento, no período 2000-2006, segundo o período de espera e a relação com o parto. Observa-se que 45,9\% das laqueaduras foram acopladas ao parto cesáreo. Tal procedimento só seria reembolsável via AlH de parto cesáreo com laqueadura tubária. Além dessas, 7,2\% foram realizadas no pós-parto, o que está em desacordo com a Portaria n. 48, de fevereiro de 1999.

Além da informação sobre a relação da laqueadura tubária com o parto, a PNDS 2006 permite examinar o tempo decorrido entre a solicitação e a realização da cirurgia. Observa-se, na Tabela 2, que o período de espera, para 23,1\% das mulheres operadas em serviços do SUS entre 2000 e 2006, foi inferior a 60 dias entre a solicitação e a operação. Restam, portanto, 492.506 cirurgias de esterilização cirúrgica feminina realizadas em serviços do SUS, no período estudado, compatíveis com a lei no que diz respeito ao tempo de espera e à relação com o parto, o que representa $23,8 \%$ do total desses procedimentos realizados no SUS sem pagamento.

Pode-se inferir que as laqueaduras de intervalo com período de espera entre a solicitação e a realização superior a 60 dias ocorreram em serviços autorizados. Do mesmo modo, é factível supor que as laqueaduras realizadas no parto cesáreo sejam justificadas por cesarianas 
anteriores ou indicação médica, o que geraria AlH de parto cesáreo com laqueadura tubária. A soma dessas AlH com aquelas de laqueadura tubária forneceria o total de procedimentos processados e pagos no Sistema de Informação Hospitalar (SIH/SUS) no período em questão.

TABELA 2

Distribuição das laqueaduras tubárias realizadas no SUS gratuitamente, segundo o período de espera e a relação com o parto

Brasil - 2000-2006

\begin{tabular}{lrr}
\hline \multicolumn{1}{c}{$\begin{array}{c}\text { Período de espera } \\
\text { e relação com parto }\end{array}$} & \multicolumn{1}{c}{$\%$} & $\begin{array}{r}\text { Frequência expandida (ponderação normalizada } \\
\text { para o total da amostra) (n. abs.) }\end{array}$ \\
\hline Parto cesáreo & 45,9 & $949.206(282)$ \\
Intervalo de confiança 95\% & $40,3-51,5$ & \\
Coeficiente de variação & 6,2 & $149.478(44)$ \\
Pós-parto & 7,2 & \\
Intervalo de confiança 95\% & $4,4-10,0$ & \\
Coeficiente de variação & 19,6 & \\
Período incompatível com a lei & 23,1 & \\
Intervalo de confiança 95\% & $18,7-27,4$ & \\
Coeficiente de variação & 9,6 & $492.506(147)$ \\
Período compatível com a lei & 23,8 & $\mathbf{2 . 0 6 8 . 3 2 1 ( 6 1 5 )}$ \\
Intervalo de confiança 95\% & $18,3-29,3$ & \\
Coeficiente de variação & 11,7 & \\
Total & $\mathbf{1 0 0 , 0}$ & \\
\hline
\end{tabular}

Fonte: Microdados da Pesquisa Nacional de Demografia e Saúde da Criança e da Mulher, PNDS 2006.

Assim, as quantidades de AlH de laqueadura tubária e de laqueadura tubária no parto cesáreo podem ser comparadas às respectivas frequências estimadas a partir dos dados da PNDS 2006. A Tabela 3 traz o número de AlH de laqueadura tubária e o de parto cesáreo com laqueadura tubária processados no país no período analisado e as respectivas frequências estimadas a partir da PNDS 2006 extraídas da Tabela 2. Também são apresentadas as proporções, em termos percentuais, das frequências de AlH processadas e pagas em relação aos totais de esterilização cirúrgica feminina estimados a partir dos dados da PNDS 2006.

TABELA 3

Número de Autorizações de Internação Hospitalar (AIH) de laqueadura tubária registradas e porcentagem em relação aos respectivos totais observados no SUS

Brasil - 2000-2006

\begin{tabular}{lr}
\hline \multicolumn{1}{c}{ Bases } & Números \\
\hline AlH (SIH-SUS) & 146.244 \\
Laqueadura tubária & 41.894 \\
Parto cesáreo com laqueadura tubária & 188.138 \\
Total & 492.506 \\
\hline PNDS 2006 & 949.206 \\
Laqueaduras tubárias compatíveis com a regulamentação & 1.441 .712 \\
Laqueaduras tubárias no parto cesáreo & \\
Total & 29,7 \\
\hline AlH/PNDS 2006 (\%) & 4,4 \\
Laqueaduras tubárias compatíveis com a regulamentação & 13,0 \\
Parto cesáreo com laqueadura tubária & \\
Total & \\
\hline
\end{tabular}

Fonte: Microdados da Pesquisa Nacional de Demografia e Saúde da Criança e da Mulher, PNDS 2006; Datasus. SIH/SUS (http://w3.datasus. gov.br/datasus). 
As AlH de laqueadura tubária constituíram 29,7\% do total observado de procedimentos potencialmente compatíveis com a lei no que se refere ao período de espera e à relação com o parto, captados pela PNDS 2006 para o período em questão (Tabela 3). De outra forma, 70,3\% das esterilizações cirúrgicas femininas do subconjunto estimado potencialmente compatível com a lei não teriam aderência com a regulamentação relativa ao período de aconselhamento. Ademais, o número de AlH de parto cesáreo com laqueadura tubária significou 4,4\%, do total estimado a partir da PNDS 2006. Este resultado indica que o acoplamento com uma cesariana, à revelia da lei, configurou-se como um mecanismo importante para a obtenção gratuita da esterilização cirúrgica feminina no sistema público de saúde.

A soma de AlH de laqueadura tubária e de parto cesáreo com laqueadura tubária representou $13 \%$ das esterilizações no parto cesáreo e de intervalo, potencialmente compatíveis com a lei, realizadas no SUS de 2000 a 2006. Ainda que sujeitos a variação amostral, os resultados da comparação entre o número de AlH de laqueadura tubária e o total de esterilizações cirúrgicas femininas estimado utilizando os dados da PNDS 2006 indicam que a provisão desse procedimento em serviços credenciados do SUS esteve muito aquém do total estimando para o período 2000-2006.

\section{Municípios com serviços credenciados para realização de laqueadura tubária em 2006 e 2013: uma aproximação}

Além dos requisitos exigidos para a realização de laqueadura tubária em serviço autorizado do SUS e de eventuais critérios extralegais de parte dos médicos, a ausência de serviço no município pode configurar-se como uma dificuldade primária para obtenção do procedimento. Em outras palavras, a inexistência de serviço autorizado no município ou em município próximo pode ser determinante para a realização do procedimento ao largo da legislação e, em última instância, para o insucesso na obtenção da laqueadura.

Para examinar a presença, por município, de serviços de planejamento familiar que ofereciam esterilização cirúrgica feminina no âmbito do SUS, foram utilizadas, novamente, as AlH de laqueadura tubária e de parto cesáreo com laqueadura processadas e pagas, segundo o município de internação, referentes a 2006 e 2013 . O emprego das AlH de 2006 deve-se ao fato de que neste ano, em comparação aos anteriores, foi registrado o maior número de AlH de laqueadura tubária, envolvendo o maior número de municípios. Logo, a rede de municípios com serviço de planejamento familiar era mais ampla em 2006 do que em qualquer um dos anos entre 2000 e 2005. A análise das AlH de laqueadura tubária processadas e pagas em 2013 visa apresentar o quadro mais recente para contrapor à situação de 2006 e oferecer um panorama do período pós-2006.

Em face da inexistência da série histórica de habilitação de hospitais do SUS autorizados a realizar o procedimento, as AlH de laqueadura tubária processadas e pagas foram empregadas como proxy da presença, no município, de serviço credenciado. A utilização desta aproximação deve-se ao fato de que o Datasus armazena somente a série mais recente de habilitações, não 
sendo possível identificar, ano a ano, os hospitais com serviço de planejamento familiar que foram posteriormente fechados. Neste aspecto, deve-se levar em conta que a ausência de registro de AlH de laqueadura tubária em determinado ano não significa, necessariamente, a inexistência de serviço credenciado.

Para identificar a existência de capacidade hospitalar para a realização da laqueadura foram utilizadas, como proxy, as AlH de clínica cirúrgica e obstétrica, excetuando-se os partos normais. Se, em um dado município, foi processada e paga pelo menos uma AlH cirúrgica ou obstétrica em 2006 e 2013, considerou-se que o mesmo apresentava serviço hospitalar hábil para a realização da laqueadura tubária no respectivo ano.

A coluna A da Tabela 4 apresenta o total de municípios do país em 2006, por região. $\mathrm{Na}$ coluna $\mathrm{B}$, encontram-se os percentuais de municípios, em relação ao total de cada região, com pelo menos uma AlH de procedimento cirúrgico ou obstétrico, exceto partos normais. A coluna C apresenta o resultado de interesse, ou seja, a proporção de municípios, por região, com registro de AlH de laqueadura tubária em relação ao total de municípios com AlH obstétrica ou cirúrgica processada e paga. Em 2006, foram geradas AlH de laqueadura tubária, isolada ou em parto cesáreo, em 13,8\% dos municípios brasileiros com capacidade potencial para realizar este procedimento cirúrgico. A Região Sudeste detinha a maior proporção (19,2\%), seguida pelo Sul (14,5\%) e Centro-Oeste (13,5\%), ao passo que as Regiões Norte e Nordeste apresentaram as menores proporções $(9,1 \%$ e $10,1 \%$, respectivamente).

TABELA 4

Percentual de municípios com AlH cirúrgica/obstétrica e com AlH de laqueadura tubária, segundo regiões Brasil - 2006-2013

\begin{tabular}{|c|c|c|c|c|c|c|c|c|}
\hline \multirow{3}{*}{ Região } & \multicolumn{4}{|c|}{2006} & \multicolumn{4}{|c|}{2013} \\
\hline & \multirow[t]{2}{*}{$\begin{array}{c}\text {-A- } \\
\text { № de } \\
\text { municípios }\end{array}$} & \multirow[t]{2}{*}{$\begin{array}{c}\text {-B- } \\
\text { Municípios com } \\
\text { AlH cirúrgica/ } \\
\text { obstétrica (1) } \\
\text { (\% de A) }\end{array}$} & \multicolumn{2}{|c|}{$\begin{array}{l}\text {-C- } \\
\text { Municípios } \\
\text { com AlH de } \\
\text { laqueadura } \\
\text { tubária }\end{array}$} & \multirow[t]{2}{*}{$\begin{array}{c}\text {-D- } \\
\text { № de } \\
\text { municípios }\end{array}$} & \multirow[t]{2}{*}{$\begin{array}{c}\text {-E- } \\
\text { Municípios com } \\
\text { AlH cirúrgica/ } \\
\text { obstétrica (1) } \\
\text { (\% de D) }\end{array}$} & \multicolumn{2}{|c|}{$\begin{array}{c}\text {-F- } \\
\text { Municípios } \\
\text { com AlH de } \\
\text { laqueadura } \\
\text { tubária }\end{array}$} \\
\hline & & & \% de B & N. abs. & & & $\overline{\% \text { de } E}$ & N. abs. \\
\hline NO & 449 & 58,6 & 9,1 & 24 & 450 & 54,9 & 24,7 & 61 \\
\hline $\mathrm{NE}$ & 1.793 & 57,0 & 10,1 & 103 & 1.793 & 39,6 & 26,3 & 187 \\
\hline SE & 1.668 & 51,8 & 19,2 & 166 & 1.668 & 45,3 & 42,7 & 323 \\
\hline SU & 1.188 & 57,4 & 14,5 & 99 & 1.191 & 45,3 & 28,4 & 153 \\
\hline $\mathrm{CO}$ & 466 & 74,7 & 13,5 & 47 & 467 & 59,7 & 39,1 & 109 \\
\hline Total & & 57,1 & 13,8 & 439 & & 45,5 & 32,9 & 833 \\
\hline N. abs. & 5.565 & 3.179 & & & 5.570 & 2.532 & & \\
\hline
\end{tabular}

Fonte: Datasus. SIH/SUS (http://w3.datasus.gov.br/datasus).

(1) Exclusive partos normais.

Esses percentuais são indicativos de uma rede de municípios com registro de $\mathrm{AlH}$ de laqueadura tubária restrita, mesmo na Região Sudeste. Se a esses achados forem acrescentados os anteriores, especialmente o ínfimo total de AlH de laqueaduras tubárias registrado no período de 2000 a 2006 em relação ao total de procedimentos realizados no 
SUS conforme captado pela PNDS 2006, a receita para a formação de uma demanda frustrada por esterilização cirúrgica feminina se completa. Pelo menos até 2006.

A Tabela 4 também apresenta essas informações para o ano de 2013. Como se observa na coluna D, foram criados cinco municípios entre 2006 e 2013. ${ }^{6}$ Nesse mesmo período, o número de municípios com pelo menos uma AlH obstétrica ou cirúrgica processada e paga decresceu em 20,4\%, passando de 3.179 para 2.532. Esta diminuição está relacionada com fatores relativos ao financiamento do SUS, ao avanço e aprimoramento da atenção básica e à transição do modelo de sistema de saúde no Brasil (RIBEIRO, 2009; MENDES et al., 2012). De qualquer maneira, esta queda enviesa a comparação da proporção de municípios com AlH de laqueadura tubária em relação ao total de municípios da região com capacidade hospitalar potencial entre 2006 e 2013.

Por este motivo, foram comparados apenas os municípios com registro de AlH de laqueadura tubária nos anos em questão (colunas C e F, Tabela 4). Como se pode notar, o número de municípios brasileiros com pelo menos uma AlH de laqueadura tubária processada e paga cresceu 89,7\%, entre 2006 e 2013, passando de 439 para 833 . O aumento mais intenso ocorreu nas Regiões Norte (154\%) e Centro-Oeste (132\%), devido, basicamente, ao pequeno número de municípios com registro de laqueadura tubária em 2006. Embora menores do que nessas regiões, os crescimentos no Sudeste $(94,6 \%)$ e no Nordeste $(81,6 \%)$ também foram vigorosos. Na Região Sul o incremento (54,5\%) foi mais modesto, mas ainda assim importante.

$\mathrm{O}$ exame da distribuição intrarregional e intraestadual de municípios com $\mathrm{AlH}$ de laqueaduras tubárias processadas e pagas em 2006 foge ao escopo deste artigo, mas é razoável supor, conforme Amorim (2008), que, diante da capacidade hospitalar necessária para efetuar o procedimento cirúrgico, prevalecessem as capitais, os municípios das regiões metropolitanas e os municípios médios. Mas, talvez mais importante, a existência de serviços credenciados depende de iniciativa política, organizacional e operacional dos gestores estaduais da saúde e, principalmente, dos gestores municipais, bem como de recursos profissionais e infraestrutura, variando, por isso, de Estado para Estado. Tomem-se os casos do Ceará e Alagoas a título de exemplo. Dos 1.794 municípios da Região Nordeste, em 2006 e 2013, 10,3\% eram cearenses e 5,7\% alagoanos. Entretanto, do total de municípios nordestinos com registro de AlH de laqueadura tubária, 23,9\% (103), em 2006, e 31,5\% (187), em 2013, pertenciam ao Ceará. Na outra ponta, Alagoas tinha apenas um município, a capital, com registro de AlH de laqueadura tubária em 2006 e assim permaneceu em 2013.

Vale registrar, também, o que se passou em relação à quantidade de AlH de laqueadura tubária e de parto cesáreo com laqueadura tubária no período posterior a 2006. Entre 2007 e 2013, foram processadas e pagas 239.576 AlH do primeiro tipo e 122.993 do segundo, totalizando 362.569 procedimentos. Comparando-se esses números com os apresentados na Tabela 4, verifica-se que o número de AlH de laqueadura tubária cresceu, do primeiro para o segundo período, $164 \%$ e o de parto cesáreo com laqueadura tubária ampliou-se

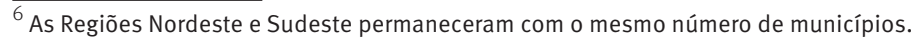


em 294\%. Essas frequências indicam que, entre 2007 e 2013, um terço das laqueaduras tubárias foi realizado em um parto cesáreo, em comparação a 22,3\% no período 2000-2006. Em face de tal incremento, esta é uma tendência na prática da laqueadura tubária no SUS merecedora de uma análise específica.

De qualquer forma, no âmbito do SUS, o quadro revelado para o período 2007-2013 é mais auspicioso do que o encontrado para o período 2000-2006. Como observado, aumentaram o número e a proporção de municípios com registro de AlH de laqueadura tubária em todas as regiões e a quantidade desse procedimento, no total do país, cresceu substancialmente. Não obstante, a rede de municípios com registro de AlH de laqueadura tubária, como proxy da existência de serviço credenciado para ofertar a esterilização cirúrgica feminina nos critérios das regulamentações da Lei n. 9.263, pode ser considerada limitada também em 2013 e, mais importante, varia sobremaneira a depender do Estado. Além de Alagoas, também no Acre, Amazonas, Roraima e Piauí houve registro de laqueadura tubária pelo SUS em apenas um município em 2006. No Maranhão, foram dois municípios. Em 2013, houve registro de AlH de laqueadura tubária em apenas um município nos Estados de Roraima e Alagoas, em dois municípios no Acre e Piauí e em oito no Maranhão.

Dada a inexistência de pesquisas sobre saúde reprodutiva e contracepção depois da PNDS 2006, não é possível avaliar, para o período 2007-2013, a relação entre o total de esterilizações cirúrgicas femininas e as ocorridas no SUS, bem como sobre a aderência dessas aos critérios regulatórios da Lei n. 9.263.

\section{Demanda frustrada por laqueadura tubária}

Os resultados apresentados nas seções anteriores indicam que o SUS, em relação ao setor privado de saúde, foi a principal fonte de laqueadura tubária no período 2000-2006 e que, apesar do declínio da participação desse procedimento no mix contraceptivo observado entre 1996 e 2006, 76,2\% das esterilizações cirúrgicas femininas não pagas ocorridas no SUS no período estudado foram efetuadas fora dos critérios estipulados pelas regulamentações da Lei n. 9.263 no que se refere à relação com parto e ao período mínimo de espera para aconselhamento. Esses achados dizem respeito às laqueaduras concretizadas.

É possível que para casais e mulheres com certas características ou em determinadas situações esses critérios constituam obstáculos intransponíveis, tornando a obtenção da laqueadura tubária desejada inalcançável, mesmo à revelia da legislação. Essa hipótese pode ser examinada a partir do questionário da PNDS 2006,7 que incluiu dois quesitos que pesquisaram o desejo e a tentativa efetiva de obter a laqueadura tubária entre as mulheres alguma vez unidas e não esterilizadas. 0 quesito 386 inquiriu se a entrevistada "alguma vez quis fazer esterilização". Para as que responderam “sim”, o quesito seguinte, 387, pesquisou “o que aconteceu que não fez a esterilização”. As opções de resposta eram: (1) não sabia

\footnotetext{
7 Pesquisa Nacional de Demografia e Saúde da Criança e da Mulher - PNDS 2006: Questionário da Mulher. Disponível em: 〈http://bvsms.saude.gov.br/bvs/pnds/banco_dados.php〉. Acesso em: 10 abr. 2010.
} 
onde conseguir; (2) tentou e o serviço de saúde não concordou; (3) tentou e não conseguiu; (4) desistiu; (5) o marido não concordou; e (6) outro.

Para estimar a prevalência contraceptiva que incorpore as tentativas efetivas, porém frustradas, de obtenção por laqueadura tubária, as mulheres unidas de 21 a 25 anos com pelo menos dois filhos vivos e cujo último nascimento tenha sido à idade mínima de 21 anos e as mulheres unidas com 26 anos de idade ou mais que responderam "sim" no quesito 386 e (2), (3) ou (5) no quesito 387 foram classificadas como se esterilizadas tivessem sido. Como não foi levantada a idade ou ano em que a tentativa de obtenção foi feita, este procedimento evita, ao menos, a inclusão de mulheres cuja idade ao nascimento do segundo filho era inferior ao estabelecido pela Portaria n. 144 para a solicitação da laqueadura (BRASIL, 1997).

A adoção dos cortes de idade em 21 e 26 anos baseou-se no item 3.4 da Portaria n. 144 e nas disposições do Código Civil Brasileiro de 1916 e de 2002. ${ }^{8}$ No que se refere a capacidade civil, idade e número de filhos, são duas as possibilidades que imputam o direito à requisição da esterilização cirúrgica no sistema público de saúde: capacidade civil plena e maiores de 25 anos de idade; ou capacidade civil plena e pelo menos dois filhos. Até 2002, a capacidade civil plena era alcançada ao se completar 21 anos de idade, ressalvadas as condições dispostas nos artigos 5ํ e 6ำ do Código Civil de 1916 (BRASIL, 2003). Ressalvadas as condições dispostas nos artigos 3ํㅜ 4ํe 5ํ do Código Civil de 2002, desde 2003 a capacidade civil plena é obtida ao se completar 18 anos de vida. Portanto, a segunda condição relativa a capacidade civil plena, idade e número de filhos presente na Portaria n. 144 era preenchida, até 2002, com a idade completa de 21 anos e pelo menos dois filhos. A partir de 2003, esta condição passou a ser preenchida com a idade completa de 18 anos e pelo menos dois filhos.

Diante do exposto, poder-se-ia ter sido mais rigoroso analiticamente, alterando-se o critério de idade a partir de 2003, inclusive, e considerando direito de toda mulher com pelo menos 18 anos de idade e no mínimo dois filhos a obtenção da laqueadura tubária no sistema público de saúde. Não obstante, como indica a literatura, na percepção e prática dos profissionais de saúde que atuam na provisão de laqueadura tubária no âmbito do SUS, quanto mais jovem maior é a chance de arrependimento após a laqueadura (OSIS et al., 2009). Por esses motivos, adotou-se, neste artigo, o critério mais restritivo de idade, que vigorava na época da sanção da Lei n. 9.263, em 1997, ou seja, a definição etária do Código Civil de 1916 - 21 anos - para o término da minoridade e aquisição da capacidade civil plena. Como precaução adicional, adotou-se a idade de 26 anos completos para a primeira condição.

Utilizando-se esses cortes etários, foi estimada a distribuição percentual da prevalência contraceptiva hipotética sob a hipótese de que as mulheres unidas de 15 a 49 anos que responderam "sim" no quesito 386 e (2), (3) ou (5) no quesito 387 obtiveram a laqueadura tubária. Deve-se considerar que esta é uma estimativa aproximada, mas conservadora, pois não incorpora 19\% das que tentaram e responderam que desistiram (opção 4 do quesito

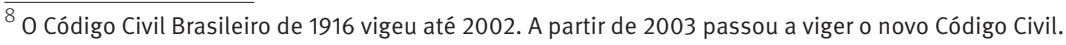


387), sem explicitação da razão. Como discutido anteriormente, é razoável supor que parte das desistências tenha ocorrido devido à extensão do período de espera (CARVALHO et al., 2007; VIEIRA; SOUZA, 2009) e que, portanto, essas desistentes teriam efetivamente tentado.

A primeira coluna da Tabela 5 apresenta a prevalência contraceptiva observada. $\mathrm{Na}$ segunda coluna são acrescentadas as mulheres unidas de 15 a 49 anos de idade que informaram ter tentado, mas o serviço de saúde não concordou. A terceira coluna mostra a prevalência contraceptiva relativa incluindo as que informaram ter tentado e não conseguido, sem especificação do motivo. A prevalência que seria observada com a incorporação daquelas cujos cônjuges não concordaram constitui a última coluna da Tabela 5. Assim, as distribuições proporcionais da prevalência contraceptiva nas colunas 2, 3 e 4 são hipotéticas e cumulativas.

TABELA 5

Distribuição observada do uso de métodos contraceptivos e distribuição estimada na hipótese de que as mulheres unidas de 15 a 49 anos que tentaram obter a esterilização cirúrgica fossem bem-sucedidas Brasil - 2006

\begin{tabular}{|c|c|c|c|c|}
\hline Métodos & $\begin{array}{l}\text { Observada } \\
\text { (1) }\end{array}$ & $\begin{array}{l}\text { (1) + Tentou } \\
\text { e serviço não } \\
\text { concordou } \\
=(2)\end{array}$ & $\begin{array}{c}(2)+\text { Tentou } \\
\text { e não conseguiu } \\
=(3)\end{array}$ & $\begin{array}{c}(3)+ \\
\text { Cônjuge não } \\
\text { concordou } \\
=(4)\end{array}$ \\
\hline Esterilização feminina & 29,1 & 32,6 & 35,8 & 36,7 \\
\hline Pílula & 23,4 & 22,1 & 20,6 & 20,2 \\
\hline Preservativo masculino & 13,0 & 12,2 & 11,8 & 11,7 \\
\hline Demais modernos & 10,8 & 10,2 & 9,8 & 9,6 \\
\hline Tradicionais & 4,3 & 4,1 & 3,9 & 3,8 \\
\hline Nenhum & 19,3 & 18,8 & 18,0 & 17,9 \\
\hline Sem resposta & 0,1 & 0,1 & 0,1 & 0,1 \\
\hline Total & 100,0 & 100,0 & 100,0 & 100,0 \\
\hline
\end{tabular}

Fonte: Microdados da Pesquisa Nacional de Demografia e Saúde da Criança e da Mulher, PNDS 2006. Nota: Número de observações (ponderação normalizada para o total da amostra): 9.967.

A classificação esterilização feminina como método utilizado para as entrevistadas que responderam ter efetivamente tentado obter a laqueadura tubária e para aquelas que seus cônjuges não concordaram leva a participação deste método no mix contraceptivo de 2006 a 36,7\%, ou seja, 26,2\% superior à observada nesse mesmo ano. 0 componente de maior peso (43,9\%) neste aumento é a não concordância do serviço de saúde, seguido pela não obtenção sem especificação do motivo do insucesso (41,2\%). Os restantes 14,9\% devem-se à não concordância do cônjuge.

Caso essas mulheres tivessem sido esterilizadas, a prevalência dos demais métodos necessariamente diminuiria em termos relativos. Vê-se, por exemplo, que a prevalência de contraceptivos orais decresce, relativamente, de 23,4\% (coluna 1) para 20,2\% (coluna 4), ou seja, torna-se 13,8\% menor. O mesmo ocorre com a prevalência dos métodos tradicionais, que seria 11,5\% menor, a de preservativo masculino, 10,2\% menor, e a dos demais métodos modernos, 10,6\% menor. 
Neste cenário hipotético, a proporção de mulheres entre 15 e 49 anos unidas e esterilizadas em 2006 seria 3,4 pontos percentuais inferior à observada em 1996 (40,1\%) e 7,6 pontos percentuais superior à observada em 2006. Assim, se essas mulheres que efetivamente tentaram obter a esterilização cirúrgica feminina tivessem sido bem-sucedidas, a participação deste método no mix contraceptivo de 2006 estaria mais próxima da proporção observada em 1996 do que daquela observada em 2006.

\section{Considerações finais}

A análise empreendida neste artigo mostrou que dois terços das esterilizações cirúrgicas femininas ocorridas no Brasil, entre 2000 e 2006, foram realizados em hospitais da rede pública. Desses, 5,2\% dos procedimentos foram pagos. Entre as esterilizações gratuitas, apenas 23,8\% estavam potencialmente compatíveis com as regulamentações da Lei n. 9.263 no que se refere ao período mínimo entre a solicitação e a realização da cirurgia e à relação com parto. É verdade que as laqueaduras no parto cesáreo poderiam ter ocorrido devido a cesarianas sucessivas ou por indicação médica. No entanto, as AlH geradas para esse tipo de procedimento representaram somente $4,4 \%$ do total de laqueaduras no parto cesáreo estimado a partir dos dados da PNDS 2006. No cômputo geral, as AlH envolvendo laqueadura tubária representaram 13\% do total estimado de esterilizações femininas potencialmente compatíveis com a legislação, ocorrido no SUS nos sete anos em questão. O exame das AlH de laqueadura tubária para 2006 indicou que a rede de municípios com serviços do SUS autorizados a oferecer a esterilização cirúrgica feminina naquele ano era bastante restrita. Em consequência das tentativas mal-sucedidas de obtenção da laqueadura tubária, identificouse uma demanda frustrada pelo procedimento que, caso houvesse sido atendida, elevaria a participação deste método no mix contraceptivo brasileiro de 2006 dos 29,1\% observados para 36,7\%, mais próxima dos 40,1\% observados em 1996.

Os achados para o período 2007-2013 mostram um crescimento importante no número de laqueaduras tubárias realizadas em serviços do SUS em relação ao período 2000-2006, com aumento significativo do peso de partos cesáreos com laqueadura tubária. Verificou-se, ainda, uma ampliação no número de municípios com registro de AlH de laqueadura tubária em todas as regiões brasileiras. Entretanto, há diferenças regionais e estaduais relevantes e reveladoras, como indicam os casos do Ceará e Alagoas.

Esses achados colocam em questão a dimensão potencialmente restritiva, não antecipada, da legislação para a obtenção gratuita da laqueadura tubária no SUS. A necessidade de apresentar concordância do cônjuge e a proibição da laqueadura pós-parto tendem a estimular a realização de cesarianas desnecessárias (POTTER et al., 2003) e de outros procedimentos reembolsáveis pelo SUS para acobertar a esterilização cirúrgica feminina e cobrir seus custos, da mesma forma que ocorria antes da Lei n. 9.263 (CAETANO; POTTER, 2004).

A não concordância do serviço em realizar a laqueadura tubária foi a principal razão para o insucesso das mulheres que tentaram obter o procedimento no SUS. É possível que a 
recusa esteja relacionada com a imposição de critérios mais restritivos do que os requisitos da legislação e com o desconhecimento da mesma (LUIZ; CITELI, 2000; BERQUÓ; CAVENAGHI, 2003; CARVALHO et al., 2007). A desistência, por sua vez, tende a estar associada à extensão do período de espera relacionado ao período de aconselhamento e ao fluxo administrativoburocrático desde o atendimento até a realização do procedimento (CARVALHO et al., 2007; OSIS et al., 2009; VIEIRA; SOUZA, 2009). Em outros contextos, o empecilho é a inexistência, no município, de hospital do SUS credenciado para prover a laqueadura tubária nos termos da lei (AMORIM et al., 2008).

No Brasil, como em outros países da América Latina, a provisão de contracepção moderna foi legislada e incorporada à política de saúde no contexto da descentralização do sistema público. Assim, a oferta de métodos em serviços públicos tende a padecer dos mesmos males que as demais áreas da saúde, tais como disfunção entre o nível central e o nível local, falta de mecanismos de estímulo para o estabelecimento de serviços e sanção para a não aderência às normas, descontinuidades derivadas das mudanças dos gestores a cada eleição, entre outros (CAETANO, 2014).

Ademais, em políticas públicas concebidas centralmente e implementadas localmente - a descentralização da saúde e o Programa Bolsa Família são paradigmáticos -, a regulamentação e as iniciativas centrais buscam induzir a organização e a melhoria dos serviços essenciais locais (ARRETCHE, 1999). Um exemplo pertinente é o Índice de Gestão Descentralizada (IGD) no caso da inclusão de famílias e atualização das informações do Cadastro Único, do Ministério de Desenvolvimento Social e Combate à Fome. ${ }^{9}$

No caso da esterilização cirúrgica feminina, deve-se considerar que a Lei n. 9.263 e as portarias que a regulamentam não estabelecem estímulos para a organização de serviços de planejamento familiar por parte dos gestores de saúde municipais. Tampouco foram previstas sanções para o descumprimento da lei por parte de médicos e serviços (VIEIRA; FORD, 2004). Portanto, a oferta de laqueadura no setor público, de acordo com a lei de planejamento familiar, depende da perspectiva e da diligência dos gestores de saúde estaduais e, mormente, de cada município.

É bastante provável que a legislação do planejamento familiar teve consequências não antecipadas que tendem a restringir a obtenção da laqueadura tubária no SUS nos termos da lei. Porém, a mera existência de legislação específica não tem, por si só, o poder da transubstanciação. Sem mecanismos de estímulo à implantação de serviços no nível local, bem como sanções para o descumprimento da legislação, a Lei n. 9.263 e suas regulamentações tendem a ser apenas letra.

\footnotetext{
${ }^{9}$ Disponível em: 〈http://www.mds.gov.br/bolsafamilia/gestaodescentralizada/indice-de-gestao-descentralizada-igd〉. Acesso em: 12 nov. 2013.
} 


\section{Referências}

AMORIM, F. A.; CAVENAGHI, S.; ALVES, J. E. D. Mudanças recentes no uso de métodos contraceptivos no Brasil e na Colômbia: com especial menção à esterilização masculina e feminina. In: WONG, L. R. (Ed.). Población y salud sexual y reproductiva en América Latina. Rio de Janeiro: Alap, v. 4, 2008, p.101-130 (Serie Investigaciones).

ARRETCHE, M. T. S. Políticas sociais no Brasil: descentralização em um Estado federativo. Revista Brasileira de Ciências Sociais, v. 14, p. 111-141, 1999. Disponível em: 〈http://www.scielo.br/scielo. php?script=sci_arttext\&pid=S0102-69091999000200009\&nrm=iso>.

BARROSO, C. Esterilização feminina: liberdade e opressão. Revista de Saúde Pública, v. 18, 1984.

BERQUÓ, E. Brasil, um caso exemplar a espera de uma açao exemplar: anticoncepção e partos cirúrgicos. Estudos Feministas, v. 1, n. 2, p. 366-381, 1993.

. A saúde reprodutiva das mulheres na 'década perdida'. São Paulo: Cebrap, 1995.

BERQUÓ, E.; CAVENAGHI, S. Direitos reprodutivos de mulheres e homens face à nova legislação brasileira sobre esterilização voluntária. Cadernos de Saúde Pública, v. 19, n. 2, p. 441-453, 2003.

BRASIL. Congresso Nacional. Exame da incidência da esterilização em massa de mulheres no Brasil. Brasília: Comissão Parlamentar de Inquérito, 1993.

BRASIL. Ministério da Saúde. Manual técnico operacional do Sistema de Informação Hospitalar 2010 - Versão 01.2012. Brasília: Secretaria de Atenção à Saúde/Departamento de Regulação, Avaliação e Controle/Coordenação Geral de Sistemas de Informação, 2012.

. Portaria n. 144, de 20 de novembro de 1997. Diário Oficial da União, 24 de novembro de 1997. Disponivel em: 〈http://sna.saude.gov.br/legisla/legisla/plan_f/SAS_P144_97plan_f.doc〉.Acesso em: 15 dez. 2013.

Portaria n. 1.230, de 14 de outubro de 1999. Diário Oficial da União, 18 de outubro de 1999a. Disponivel em: 〈http://dtr2001.saude.gov.br/sas/PORTARIAS/Port99/GM/GM-1230.html〉. Acesso em: 14 dez. 2013.

Portaria n. 48, de 11 de fevereiro de 1999. Diário Oficial da União, 17 de fevereiro de 1999b. Disponivel em: 〈http://dtr2001.saude.gov.br/sas/PORTARIAS/Port99/PT-048.html〉. Acesso em: 13 abr. 2008.

Portaria n. 2.848, de 6 de novembro de 2007. Diário Oficial da União, 07 de novembro de 2007. Disponivel em: 〈http://dtr2001.saude.gov.br/sas/PORTARIAS/Port2007/GM/GM-2848.htm〉. Acesso em: 24 dez. 2013.

BRASIL. Presidência da República. Lei n. 9.263, de 12 de janeiro de 1996. Diário Oficial da União, 15 de janeiro de 1996. Disponivel em: 〈http://www.planalto.gov.br/ccivil_03/leis/19263.htm〉. Acesso em: 15 jan. 2000.

BRASIL. Senado Federal. Código Civil: quadro comparativo 1916/2002. Brasília: Subsecretaria de Edições Técnicas, 2003.

BUSSAB, W. D. O.; MORETTIN, P. A. Estatística básica. 6a ed. São Paulo: Ed. Saraiva, 2010.

CAETANO, A. J. Ascensão e queda da laqueadura tubária no Brasil: uma avaliação das pesquisas de demografia e saúde de 1986, 1996 e 2006. In: XVII ENCONTRO DA ASSOCIAÇÃO BRASILEIRA DE ESTUDOS POPULACIONAIS. Anais... Caxambu MG, 20-24 de setembro 2010.

Diferenciais no acesso e uso de métodos contraceptivos modernos: Colômbia, Peru e Honduras. In: WONG, L. R. et al. (Eds.). Cairo+20: perspectivas de la agenda de población y desarrollo sostenible después de 2014. Rio de Janeiro: Alap, 2014, p.149-162. 
CAETANO, A. J.; POTTER, J. E. Politics and female sterilization in the Brazilian Northeast. Population and Development Review, v. 30, n. 1, 2004.

CARVALHO, L. E. C. D. et al. Esterilização cirúrgica voluntária na Região Metropolitana de Campinas, São Paulo, Brasil, antes e após sua regulamentação. Cadernos de Saúde Pública, v. 23, p. 2906-2916, 2007. Disponivel em: 〈http://www.scielo.br/scielo.php?script=sci_arttext\&pid=S0102311X2007001200012\&nrm=iso>.

DINIZ, S.; SOUZA, C. M.; PORTELLA, A. P. Not like our mothers: reproductive rights and the emergence of citizenship among rural workers, domestic workers and housewives. In: PETCHESKY, R.; JUDD, K. (Eds.). Negotiating reproductive rights. Women's perspectives across countries and cultures. London: Zed Books, 1998.

GELEDÉS. Esterilização: impunidade ou regulamentação? São Paulo: Geledés - Instituto da Mulher Negra, 1991.

LUIZ, O. D. C.; CITELI, M. T. Esterilização cirúrgica voluntária na Região Metropolitana de São Paulo: organização e oferta de serviços, 1999. São Paulo: Comissão de Cidadania e Reprodução, 2000.

MARTINE, G. Brazil's fertility decline, 1965-95: a fresh look at key factors. Population and Development Review, v. 22, n. 1, p. 47-75, Mar. 1996. Disponivel em: 〈Go to |SI〉://A1996UH92400003〉.

MENDES, A. D. C. G. et al. Assistência pública de saúde no contexto da transição demográfica brasileira: exigências atuais e futuras. Cadernos de Saúde Pública, v. 28, p. 955-964, 2012. Disponivel em: 〈http:// www.scielo.br/scielo.php?script=sci_arttext\&pid=S0102-311X2012000500014\&rm=iso>.

MERRICK, T. W.; BERQUÓ, E. The determinants of Brazil's recent rapid decline in fertility. Washington D.C.: National Academy Press, 1983.

OSIS, M. J. D. et al. Atendimento à demanda pela esterilização cirúrgica na Região Metropolitana de Campinas, São Paulo, Brasil: percepção de gestores e profissionais dos serviços públicos de saúde. Cadernos de Saúde Pública, v. 25, p. 625-634, 2009. Disponível em: 〈http://www.scielo.br/scielo. php?script=sci_arttext\&pid=S0102-311X2009000300017\&nrm=iso>.

PERNAMBUCO. Assembleia Legislativa. Esterilização feminina em Pernambuco. Relatório Final. Recife: Assembleia Legislativa, 1992.

PERPÉTUO, I. H. O.; WAJNMAN, S. Socioeconomic correlates of female sterilization in Brazil. In: CICREDISUNAM SEMINAR ON POVERTY, FERTILITY AND FAMILY PLANNING. Cidade do México, 2-4 junho 1998.

PERPÉTUO, I. H. O.; WONG, L. R. Desigualdade socioeconômica na utilização de métodos anticoncepcionais no Brasil: uma análise comparativa com base nas PNDS1996 e 2006. In: MINISTÉRIO DA SAÚDE; CEBRAP (Eds.). Pesquisa Nacional de Demografia e Saúde da Criança e da Mulher PNDS 2006: dimensões do processo reprodutivo e da saúde da criança. Brasília: Ministério da Saúde, v.1, p. 85-104, 2009 (Série G - Estatística e Informação em Saúde).

POTTER, J.; PERPÉTUO, I.; AL, E. Frustrated demand for postpartum female sterilization in Brazil. Contraception, v. 67, p. 385-390, 2003.

RIBEIRO, J. M. Desenvolvimento do SUS e racionamento de serviços hospitalares. Ciência \& Saúde Coletiva, v. 14, p. 771-782, 2009. Disponível em: 〈http://www.scielo.br/scielo.php?script=sci_ arttext\&pid=S1413-81232009000300013\&nrm=iso .

SANTOS, A. C. D. Sistema de informações hospitalares do Sistema Único de Saúde: documentação do sistema para auxiliar o uso das suas informaç̧̃es. Dissertação (Mestrado). Escola Nacional de Saúde Pública Sergio Arouca, Rio de Janeiro, 2009.

VIEIRA, E. M.; FORD, N. J. Provision of female sterilization in Ribeirão Preto, São Paulo, Brazil. Cadernos de Saúde Pública, v. 20, n. 5, p. 1201-1210, 2004. 
VIEIRA, E. M.; SOUZA, L. D. Acesso à esterilização cirúrgica pelo Sistema Único de Saúde, Ribeirão Preto, SP. Revista de Saúde Pública, v. 43, p. 398 - 404, 2009.

\title{
Sobre 0 autor
}

André Junqueira Caetano tem pós-doutorado no Departamento de Estatística Social e Demografia da University of Southampton, doutor em Sociologia com especialização em Demografia pela University of Texas at Austin e mestre em Demografia pelo Cedeplar-UFMG. Professor da Pontifícia Universidade Católica de Minas Gerais - PUC Minas.

\section{Endereço para correspondência}

Av. Itaú, 505

30535-012 - Belo Horizonte-MG, Brasil

\begin{abstract}
Female surgical sterilization in Brazil, 2000 to 2006: Compliance with the family planning law and frustrated demand
\end{abstract}

Brazilian Act 9263, of 1996, ended a historic omission by the Brazilian State regarding family planning policies. Among other provisions, the law legalized surgical sterilization in the public health system. In contrast, Ministry of Health ordinances No. 144, of 1997, and No. 48, of 1999, set down potentially restrictive criteria for obtaining tubal ligation in compliance with law. If non-compliance with the regulation is related to the mandatory 60 -day counselling period and to the prohibition of tubal ligation until the 42nd day postpartum, some refusals by professionals involved in providing ligation result from these individuals' personal perceptions and attitudes regarding criteria such as age and number of children, and regarding the possible implications of the sterilization for the petitioner. Explicit and implicit refusals result in frustrated demand. The same logic applies to the municipal level of health management and is reflected in the non-existence of accredited services in most municipalities with hospital capacity to offer the procedure. Employing data from the 2006 PNDS and hospitalization authorization records, this paper first examines compliance with the regulation on tubal sterilizations performed in the Federal Public Health System (SUS) between 2000-2006 as well as the number of municipalities, even with accredited hospitals in 2006 and 2013. The frustrated demand is examined on the basis of information from the PNDS (DHS) 2006 regarding failed attempts due to refusals of the service sought, failure to provide motives, and non-consent by spouses.

Keywords: Reproductive health. Family planning law. Contraception. Tubal ligation. Frustrated demand. Brazil.

\section{Resumen}

Esterilización quirúrgica femenina en Brasil, 2000 a 2006: adhesión a la ley de planificación familiar y demanda frustrada

La Ley No 9.263, de 1996, puso fin a una omisión histórica del Estado brasileño en el ámbito de la planificación familiar, además de legislar sobre la prestación de la esterilización quirúrgica en el sistema público de salud. Sin embargo, las ordenanzas del Ministerio de Salud № 144, de 1997, y No 47, de 1999, contienen criterios potencialmente restrictivos para la obtención de la ligadura de trompas de 
conformidad con las reglamentaciones. En tanto que la no adhesión a la reglamentación se relaciona con el período de consejería obligatorio de 60 días y la prohibición de la esterilización hasta los 42 días después del parto, parte de las negaciones de los profesionales involucrados en la prestación del procedimiento resultan de sus percepciones y posturas sobre criterios como la edad y el número de hijos y sobre las posibles consecuencias para la solicitante. Los rechazos explícitos o implícitos producen una demanda frustrada. Esta lógica se aplica al nivel municipal de la gestión de salud y se refleja en la falta de servicios acreditados en la mayoría de los municipios con capacidad hospitalaria para ofrecer el procedimiento. Empleando datos de la Pesquisa Nacional de Demografia e Saúde (PNDS) de 2006 y de las autorizaciones de internación hospitalaria, este artículo examina la adhesión a la regulación de las esterilizaciones quirúrgicas femeninas realizadas en el Sistema Único de Saúde (SUS) en el período 2000-2006 y la extensión de la red de municipios con servicios acreditados en 2006 y 2013. La demanda frustrada se analiza a partir de la información provista por la PNDS de 2006 sobre los intentos fallidos de obtención del servicio debidos a su negación, los casos de no obtención cuyo motivo no está especificado y la negativa del cónyuge.

Palabras clave: Salud reproductiva. Ley de Planificación Familiar. Contracepción. Ligadura de trompas. Demanda frustrada. Brasil.

Recebido para publicação em 28/03/2014 Aceito para publicação em 18/11/2014 
